\title{
Compensatory Changes in the Function of the Remaining Kidney Immediately after Unilateral Nephrectomy in Sheep
}

\author{
Gaber Ziada, ${ }^{1}$ Husein Youseif ${ }^{2}$ and Magdy Khalil $^{1}$ \\ ${ }^{1}$ Department of Nuclear Medicine Faculty of Medicine, Kuwait University, Kuwait City, Kuwait \\ ${ }^{2}$ Department of surgery, ministry of public health, Kuwait City, Kuwait
}

Live kidney donation is an established form of organ donation but carries the risk of an unnecessary surgery in a normal individual for the benefit of the recipient. Despite a number of recent studies on the renal function of long-term kidney donors, little attention has been paid to the damaging effects of compensatory hyper-filtration on renal tubular cells immediately after donor nephrectomy. The present study therefore aimed to examine the immediate changes in renal function of the remaining kidney using a sheep model of unilateral nephrectomy. We used the gamma camera-based method to measure the glomerular filtration rate and the tubular excretion values after simultaneous injection of ${ }^{99 \mathrm{~m}} \mathrm{Tc}$-diethylene triamine pentaacetic acid and ${ }^{131}$ I-ortho-iodohippurate tracers. Compared were the differences in the functions between the remaining left kidney immediately after clamping the right renal pedicle and the baseline values that were measured one week before unilateral nephrectomy. After radionuclide data acquisition was completed, the right kidney was removed. The mean glomerular filtration rate (GFR) increased by $52.3 \%$ from the baseline values $(29.5 \pm 2.7$ to $45.0 \pm 6.7 \mathrm{ml} / \mathrm{min} ; n=40, p<0.001)$, while the mean effective renal plasma flow (ERPF) increased by $40 \%(225.5 \pm 27.8$ to $357.8 \pm 38.94 \mathrm{ml} / \mathrm{min} ; p<0.001)$, respectively. Mean filtration fraction was increased from 0.117 to 0.127 immediately after nephrectomy $(p<0.001)$. We conclude that after unilateral nephrectomy the remaining kidney immediately compensates for the loss of a donated kidney by increasing glomerular filtration rate and effective renal plasma flow. —— Radionuclides; GFR; ERPF; Unilateral nephrectomy; sheep.

Tohoku J. Exp. Med., 2009, 219 (2), 165-168. 두 2009 Tohoku University Medical Press

After removal of a normal kidney for the purpose of transplant donation, functional adaptation and compensatory hypertrophy of the remaining kidney takes place, so as to approach the functional capacity of both kidneys prior to unilateral nephrectomy. The mechanisms of compensatory renal growth still remain a mystery till now. Various growth factors, including growth hormone, insulin-like growth factor-1 have been implicated in different forms of compensatory renal growth change (Yildiz et al. 2007). A number of recent studies of long-term kidney donors have reviewed glomerular function and blood pressure. Little attention has been paid to the potentially damaging effects of compensatory hyper filtration on renal tubular cells after donor nephrectomy (Chamberlain and Shirley 2006). The creatinine clearance increases to $70 \%$ of the preoperative values within several weeks (Boudville et al. 2006) and remained stable for more than 10 years after unilateral nephrectomy change (Garg et al. 2006). The serum creatinine level increased up to $20 \%$ above baseline, remaining within the normal range (Sahay et al. 2007). The lowmolecular-weight protein cystatin $\mathrm{C}$ found to correlate well with all other markers of kidney function and was able to detect acute changes in kidney function immediately post unilateral nephrectomy change (Gourishankar et al. 2008). Kidney enlargement had been estimated radiologically and shown a $20 \%$ increase in the volume of the remaining kidney (Khosroshahi et al. 2005; Cozzi et al. 2007). Furthermore, the functional adaptation of the remaining kidney after unilateral nephrectomy was found to have a rapid onset, more for glomerular function than for tubular function. Human studies at short term (1-6 days) showed a significant increase in glomerular filtration rate (GFR) (Textor et al. 2004; Bridget et al. 2007). The postoperative effective renal plasma flow (ERPF) measured by the clearance of para-aminohippuric acid (PAH) (Sangeeta et al. 2002) or ${ }^{131}$ I-orthoiodo-hippurate (Chang et al. 2008) increased by about $30 \%$ as early as one week after surgery and remained above the pre-nephrectomy level even after 10 years (Prasad et al. 2008). Renal scintigraphy is a noninvasive, reproducible test that monitors changes in individual renal function (Taylor 1982; He and Fischman 2008). It was found that the compensatory increase in the absolute uptake of ${ }^{99 \mathrm{~m}} \mathrm{Tc}$ dimercaptosuccinic acid (DMSA) by the remaining kidney was associated with an increase in the renal volume. The

Received July 7, 2009; revision accepted for publication August 24, 2009. doi:10.1620/tjem.219.165

Correspondence: Gaber Ziada Ph.D., Department of Nuclear Medicine, Faculty of Medicine, Kuwait University, P.O. Box 24923, Safat,

13110 Kuwait, Kuwait.

e-mail: gz555@hotmail.com 
function of the remaining kidney increased to $79.1 \%$ of the total preoperative renal function compared with 56.8\% before surgery (Kawamura et al. 1978; Ben-Haim et al. 2000). The average percentage increase in mercapto acetyl tri-glycine (MAG3) clearance of the remaining kidney was increased to $39.5 \%$ after one month and to $40.5 \%$ after one year (Shirasaki et al. 2004). Furthermore, the renal functional reserve in kidney donors was assessed using scintigraphy with ${ }^{99 \mathrm{~m}} \mathrm{Tc}$-diethylene-triamine-pentaacetic-acid (DTPA). The GFR of the remaining kidney increased by $22.8 \%$ after four weeks after donor nephrectomy, and increased by $59.7 \%$ after 6 months (George et al. 1996). However, to the best of our knowledge, acute changes in renal function after unilateral nephrectomy change have not been sufficiently investigated with nuclear medicine techniques.

In the present study, we aimed to characterize the changes in GFR, ERPF and filtration fraction (FF) in the remaining kidney before and immediately after unilateral nephrectomy change in sheep, and to monitor changes that may predict the immediate postoperative chronic renal failure or insufficiency.

\section{Materials and Methods}

Animals

A total of 40 domestic sheep of both sexes weighting between 30 and $40 \mathrm{~kg}$ were used in this experiment. The animals were brought in one week before the experiment and kept in the animal house to reduce the stress of transport. They were fasted before surgery for 16 hours, but they have free access to water. The protocol of this project was approved by the Animal Research Committee, the health science center, Kuwait University.

\section{Surgical preparation}

An intravenous cannula (gauge 20) was inserted into the long saphenous vein and was fixed to the skin. General anesthesia was induced using 4-5 mg/ $\mathrm{kg}$ of body weight of sodium thiopentodne i.v. (Pentothal; Abbott, Kurnell, NSW, Australia). An endotracheal tube of size 7 and nasogastric tube were inserted. Anesthesia was maintained with 2-3\% halothane (Fluothane; ICI, Macclesfield, Cheshire, UK) in $\mathrm{O}_{2}$ (Amanda et al. 2002). This technique provided a stable hemodynamic status during the entire duration of anesthesia. Good hydration was maintained by infusing sodium chloride $10-15 \mathrm{ml} / \mathrm{kg}$ intravenously. A gamma camera acquisition was performed one week before unilateral nephrectomy and renal functions under baseline were calculated for every kidney separately.

\section{Surgical Technique}

Unilateral nephrectomy was performed to all animals included in the study. Under aseptic conditions, a sub-costal incision in the skin was made and extended from the renal angle to a suitable distance anteriorly. With avoidance of the sub-costal nerve, the external and internal oblique muscles as well as the transverse muscle were cut. Through retroperitoneal approach, the kidney was dissected from the surrounding perinephric fat, and the renal vessels were exposed. The gamma camera acquisition started immediately after clamping the renal pedicle (unilateral nephrectomy). GFR, ERPF, and FF were calculated for every kidney separately. When radionuclide data acquisition was completed, the right kidney was removed and the wounds were closed in layers. Intramuscular injection of $600 \mathrm{mg}$ of procaine penicillin and $750 \mathrm{mg}$ of dihydrostreptomycin sulfate were given to the sheep and continue for the next 2 days. Animals were housed in metabolic cages in a room maintained between 18 and $23^{\circ} \mathrm{C}$. They were given free access to water and to 1,200 g Lucerne chaff, $300 \mathrm{~g}$ oats and $6 \mathrm{~g}$ sodium chloride daily.

\section{Imaging Techniques}

The precise measurement of the GFR and the renal plasma flow usually requires continuous intravenous administration of adequate substances, with multiple blood and urine analysis, and does not allow measurement of separate renal function. Molecular imaging techniques are of primary importance in the initial diagnosis and followup of many renal diseases, enabling early detection of disease, often before structural changes are apparent. It facilitates noninvasive isotopic methods for measurement of GFR, ERPF and FF. We used the Gamma Camera-based method to analyze the early rise of the kidneys' time-activity curves which were obtained after simultaneous injection of ${ }^{99 \mathrm{~m}}$ Tc-DTPA to measure glomerular filtration (Gates 1982) and ${ }^{131}$ I-ortho-iodohippurate tracers to measure tubular excretion (Schlegel et al.1979). The technique requires attenuation correction, but no blood or urine sampling. The injected dose was measured by counting the syringe on the gamma camera under standardized geometry (at $20 \mathrm{~cm}$ ). Renal data acquisition was performed with the gamma camera while the sheep's set up in a supine position over the camera. The dynamic acquisition data was recorded in computer memory every $15 \mathrm{sec}$ for $\left({ }^{99 \mathrm{~m}} \mathrm{Tc}\right.$-DTPA) and every $60 \mathrm{sec}$ for ( ${ }^{131} \mathrm{I}$-Hippuran). Data acquisition was initiated one week before surgery and was considered as the base line parameter. After one week, the data acquisition was repeated again but immediately after clamping the renal pedicle and was considered as the immediate change parameter after unilateral nephrectomy. Both data were analyzed at the end of each study, after outlining a region of interest for each kidney and for the background activity. In practice, each measurement for 3-4 $\mathrm{min}$ is sufficient to estimate the GFR and the ERPF. FF was calculated as GFR divided by ERPF with no corrections

\section{Statistical Analysis}

Mean \pm S.D. of all the parameters was calculated. The student paired $t$ test was used to determine the difference in various parameters of the renal function between the baseline scan and those measured immediately after unilateral nephrectomy change. Parameters having $p$ value less than 0.05 was considered as significant change (SPSS version 17-4).

Table 1. Renal function before and immediately after unilateral nephrectomy.

\begin{tabular}{llc}
\hline & $\begin{array}{c}\text { Baseline values and values } \\
\text { after surgery }\end{array}$ & Mean \pm s.D. \\
\hline GFR $(\mathrm{ml} / \mathrm{min})$ & Baseline & $29.55 \pm 2.7$ \\
& Immediately after Surgery & $45.00 \pm 6.7$ \\
ERPF (ml/min) & Baseline & $255.55 \pm 27.8$ \\
& Immediately after Surgery & $357.77 \pm 38.9$ \\
Filtration fraction & Baseline & $0.117 \pm 0.018$ \\
& Immediately after Surgery & $0.127 \pm 0.02$ \\
\hline
\end{tabular}


Table 2. Paired Samples Test obtained before and after uninephrectomy.

\begin{tabular}{llcc}
\hline & & correlation & $P$-value \\
\hline GFR $(\mathrm{ml} / \mathrm{min})$ & Before and immediately after surgery & 0.695 & 0.001 \\
ERPF $(\mathrm{ml} / \mathrm{min})$ & Before and immediately after surgery & 0.879 & 0.001 \\
FF & Before and immediately after surgery & 0.974 & 0.001 \\
\hline \multicolumn{2}{c}{$P<0.05$ was considered for statistical significance. }
\end{tabular}

\section{Results}

Comparisons were made between the difference in functions between the remaining kidney immediately after surgery and the baseline values. Mean post-uninephrectomy GFR and ERPF increased instantaneously by $52.3 \%$ and $40 \%$, respectively. The mean compensatory increase in the GFR measurements was found to be $29.5 \pm 2.7$ and 45.0 $\pm 6.7 \mathrm{ml} / \mathrm{min}$, respectively $(p<0.001)$. The mean ERPF was found to be $225.5 \pm 27.8$ and $357.8 \pm 38.9 \mathrm{ml} / \mathrm{min}$, respectively $(p<0.001)$ (Tables 1 and 2$)$. The absolute uptake values of the filtration fraction were increased from $0.117 \pm 0.018$ to $0.127 \pm 0.02$ before and immediately after unilateral nephrectomy $(p<0.001)$.

\section{Discussion}

The purpose of the study was to evaluate the differences in the GFR, ERPF and FF of the remaining kidney immediately after donor nephrectomy as acute renal compensatory hemodynamic response in sheep. Several studies have examined the effects of renal donation on the contralateral remaining kidney. It was found that hypertension, mild proteinuria, and a decrease in creatinine clearance may be developed in long-term follow-up, but these were not greater than those in the normal population (Steckler et al. 1990; Anderson et al. 1991; Goldfarb 1995; Regazzoni et al. 1998). We noticed that data on renal functions immediately after unilateral nephrectomy are lacking. Only few reports are available about the increase in GFR and ERPF in the remaining kidney after relatively short period of time, one week (Ismaili et al. 2005; Textor et al. 2004; Garg et al. 2006; Sahay et al. 2007; Prasad et al. 2008). The results of the present study confirmed the above finding and showed that there was a considerable and instantaneous increase in function of the remaining kidney immediately after unilateral nephrectomy. The mean increase involves, almost to the same extent, both the glomerular and the tubular components. The mean compensatory increase in the GFR was found to be $29.5 \pm 2.7$ and $45.0 \pm 6.7$, respectively ( $p<$ 0.001). The mean ERPF measurements were found to be $225.5 \pm 27.8$ and $357.8 \pm 38.9$, respectively $(p<0.001)$. The mean values of GFR and ERPF significantly increased by $52.3 \%$ and $40 \%$ from the baseline values (Tables 1 and 2). The compensatory increase in the absolute uptake values of FF was increased from $0.117 \pm 0.018$ to $0.127 \pm 0.02$, indicating proportionate increase of GFR compared with ERPF. This is a typical pattern that was observed with normal val- ues (Gates 2004). Our findings also support the other human studies, which showed significant increase in renal function after uninephrectomy (Ben-Haim et al. 2000; Kondo et al. 2002; Sangeeta et al. 2002; Textor et al. 2004; Bridget et al. 2007; Chang et al. 2008; Clark et al. 2008).

In conclusion, the present study supports the use of radionuclide in evaluating renal functions, which is precise technique and easy to perform. It does not require continuous intravenous administration of adequate substances, with multiple blood and urine analyses, and it allows measurement of separate renal function. The study also shows that compensatory hyperfunction is common after unilateral nephrectomy as indicated by the immediate increase in both the GFR and the ERPF in the remaining kidney.

\section{References}

Amanda, C., Eugenie, R. \& Karen, J. (2002) Renal, cardiovascular and endocrine responses of fetal sheep at 0.8 of gestation to an infusion of amino acids. J. Physiol., 540, 717-728.

Anderson, R.G., Bueschen, A.I., Lloyd, L.K., Dubovsky, E.V. \& Burns, A.R. (1991) Short-term and long-term changes in renal function after donor nephrectomy. Urology, 145, 11-13.

Ben-Haim, S., Sopov, V. \& Stein, A. (2000) Kidney functions after radical nephrectomy: assessment by quantitative SPECT of 99mTc-DMSA uptake by the kidneys. J. Nucl. Med., 41, 1025-1029.

Boudville, N., Prasad, G.V., Knoll, G., Muirhead, N., ThiessenPhilbrook, H.,Yang, R.C., Rosas-Arellano, M.P., Housawi, A. \& Garg, A.X. (2006) Analysis: risk for hypertension in living kidney donors. Network. Ann. Intern. Med., 145, 185-196.

Bridget, K.U., Tillson, D.M., Smith, C.M., Brawner, W.R., Almond, G.T., Beard, D.M., Lenz, S.D. \& Lothrop, C.D. Jr. (2007) Evaluation of clinical status, renal function and hematopoietic variables after unilateral nephrectomy in canine kidney donors. J. Am. Vet. Med. Assoc., 230, 1653-1656.

Chamberlain, R.M. \& Shirley, D.G. (2006) Time course of the renal functional response to partial nephrectomy measurements in conscious rats. Exp. Physiol., 92, 251-262.

Chang, S.S., Hung, C.J., Lin, Y.J., Chou, T.C., Chuang, J.P., Chung, P.Y., Lin, Y.S. \& Lee, P.C. (2008) Influence of preoperative allograft function (effective renal plasma flow) on the shortterm outcome following living donor kidney transplantation. Transplant. Proc., 40, 2108-2111.

Clark, A.T., Breau, R.H., Morash, C., Fergusson, D., Doucette, S. \& Cagiannos, I. (2008) Preservation of renal function following partial or radical nephrectomy using 24-hour creatinine clearance. Eur. Urol., 54, 143-149.

Cozzi, F., Zani, A., Schiavetti, A., Morini, F., Degaetano, V., Matrunola, M. \& Cozzi, D.A. (2007) Compensatory renal growth in children with unilateral renal tumor treated by nephrons-sparing surgery or nephrectomy. Eur. J. Pediatr. Surg., 17, 382-386.

Garg, A.X., Muirhead, N., Knoll, G., Yang, R.C., Prasad, G.V., Thiessen-Philbrook, H., Arellano, M.P., Housawi, A. \& 
Boudville, N. (2006) Proteinuria and reduced kidney function in living kidney donors: A systematic review, meta-analysis, and meta-regression. Donor Nephrectomy Outcomes Research (DONOR) Network. Kidney Int., 70, 1801-1810.

Gates, G.F. (1982) Glomerular filtration rate: estimation from fractional renal accumulation of $99 \mathrm{mTc}-\mathrm{DTPA}$ (stannous). AJR Am. J. Roentgenol., 138, 565-570.

Gates, G.F. (2004) Filtration fraction and its implications for radionuclide renography using diethylenetriaminepentaacetic acid and mercaptoacetyltriglycine. Clin. Nucl. Med., 29, 231-237.

George, J., John, G., Oommen, R., Jacob, S., Jacob, C. \& Shastry, J. (1996) Renal functional reserve in kidney donors assessed in different settings using scintigraphy. Nephron, 73, 154-157.

Goldfarb, D.A. (1995) Preservation of renal function and the risk of hyper filtration nephropathy. Semin. Urol. Oncol., 13, 292295.

Gourishankar, S., Courtney, M., Jhangri, G., Cembrowski, G. \& Pannu, N. (2008) Serum Cystatin C performs similarly to traditional markers of kidney function in the evaluation of donor kidney function prior to and following unilateral nephrectomy. Nephrol. Dial. Transplant., 23, 3004-3009.

He, W. \& Fischman, A.J. (2008) nuclear imaging in the genitourinary tract: recent advances and future directions. Radiol. Clin. North Am., 46, 25-43.

Ismaili, K., Hall, M., Ham, H. \& Piepsz, A. (2005) Evolution of individual renal function in children with unilateral complex renal duplication. J. Pediatr., 147, 208-212.

Kawamura, J., Hosokawa, S. \& Yoshida, O. (1978) Validity of ${ }^{99 m}$-Tc Dimercaptosuccinic acid renal uptake for an assessment of individual kidney function. J. Urol., 119, 305-309.

Khosroshahi, H.T., Tarzamni, M. \& Oskuii, R.A. (2005) Doppler ultrasonography before and 6 to 12 months after kidney transplantation. Transplant. Proc., 37, 2976-2981.

Kondo, T., Nakazawa, H., Ito, F., Onitsuka, S., Ryoji, O., Yago, R., Hashimoto, Y. \& Toma, H. (2002) Impact of arterial occlusion during partial nephrectomy on residual renal function: an eval- uation with ${ }^{99 \mathrm{~m}}$ technetium-dimercaptosuccinic acid scintigraphy. Int. J. Urol., 9, 435-440.

Prasad, G.V., Lipszyc, D., Huang, M., Nash, M.M. \& Rapi, L. (2008) A prospective observational study Changes in renal function and cardiovascular risk following living kidney donation. Transplantation, 86, 1315-1318.

Regazzoni, B.M., Genton, N., Pelet, J., Drukker, A. \& Guignard, J.P. (1998) Long-term follow-up of renal functional reserve capacity after unilateral nephrectomy in childhood. J. Urol., 160, 844-848.

Sahay, M., Narayen, G. \& Anuradha, A. (2007) Risk of live kidney donation-Indian perspective. J. Assoc. Physicians India, 55, 267-270.

Sangeeta, A., Emma, C., Ashok, J., Jerry, Mc., Ron, S. \& Pradip, C. (2002) Evaluation of renal function in transplant patients on tacrolimus therapy. J. Clin. Pharmacol., 42, 798-805.

Schlegel, J.U., Halikiopoulos, H.L. \& Prima, R. (1979) Determination of filtration fraction using the gamma scintillation camera. J. Urol., 122, 447-450.

Shirasaki, Y., Tomoyasu, T., Takashi, S., Yasutomo, N. \& Hiromi, K. (2004) Kidney function after nephrectomy for renal cell carcinoma. Urology, 64, 43-47.

Steckler, R.E., Riehle, R.A. \& Vaughn, E.D. (1990) Hyperfiltration-induced renal injury in normal man: myth or reality. $J$. Urol., 144, 1323-1327.

Taylor, A. (1982) Quantization of renal function with static imaging agents. Semin. Nucl. Med., 12, 330-344.

Textor, S.C., Taler, S.J., Driscoll, N., Larson, T.S., Gloor, J., Griffin, M., Cosio, F., Schwab, T., Prieto, M., Nyberg, S., Ishitani, M. \& Stegall, M. (2004) Blood pressure and renal function after kidney donation from hypertensive living donors. Transplantation, 78, 267-282.

Yildiz, B., Kural, N., Colak, O., Ak, I. \& Akcar, N. (2007) IGF-1, IGFBP-3, VEGF and MMP-9 levels and their potential relationship with renal functions in patients with compensatory renal growth. Clin. Physiol. Funct. Imaging, 28, 107-112. 